\title{
New Suzuki-Berinde type fixed point results
}

\author{
N. Hussain and J. AHMAD
}

\section{ABSTRACT.}

The aim of this article is to improve the results of Piri et al. [Fixed Point Theory and Applications 2014, 2014:210] by introducing new types of contractions say Suzuki-Berinde type $F$-contractions and Suzuki type rational $F$ contractions. We also establish a common fixed point theorem for a sequence of multivalued mappings. An example is also given to support our main results.

Acknowledgement. This article was funded by the Deanship of Scientific Research (DSR), King Abdulaziz University, Jeddah. The first author, therefore, acknowledge with thanks DSR for the technical and financial support. The second author acknowledges with thanks DSR, University of Jeddah for financial support. The authors are grateful to the learned referee for the valuable comments and suggestions.

\section{REFERENCES}

[1] Abbas, M., Ali, B. and Romaguera, S., Fixed and periodic points of generalized contractions in metric spaces, Fixed Point Theory Appl., 2013:243, (2013)

[2] Ahmad, J., Al-Rawashdeh, A. and Azam, A., New fixed point theorems for generalized F-contractions in complete metric spaces, Fixed Point Theory Appl., 2015:80, (2015)

[3] Azam, A. and Arshad, M., Fixed points of a sequence of locally contractive multivalued maps, Comput. Math. Appl., 57 (2009), No. 1, 96-100

[4] Banach, S., Sur les opérations dans les ensembles abstraits et leur applications aux équations intégrales, Fundam. Math., 3 (1922), 133-181

[5] Berinde, V., Approximating fixed points of weak contractions using the Picard iteration, Nonlinear Anal. Forum, 9 (2004), 43-53

[6] Berinde, V., General constructive fixed point theorem for Ćirić-type almost contractions in metric spaces, Carpath. J. Math., 24 (2008), 10-19

[7] Ćirić, L., Abbas, M., Saadati, R. and Hussain, N., Common fixed points of almost generalized contractive mappings in ordered metric spaces, Appl. Math. Comput., 217 (2011), 5784-5789

[8] Hussain, N. and Salimi, P., Suzuki-Wardowski type fixed point theorems for $\alpha$-GF-contractions, Taiwanese J. Math., 18 (2014), 1879-1895

[9] Hussain, N., Ahmad, J., Ćirić, L. and Azam, A., Coincidence point theorems for generalized contractions with application to integral equations, Fixed Point Theory Appl., 2015:78, (2015)

[10] Hussain, N., Ahmad, J. and Azam, A., On Suzuki-Wardowski type fixed point theorems, J. Nonlinear Sci. Appl., 8 (2015), 1095-1111

[11] Hussain, N. and Taoudi, M. A., Krasnosel'skii-type fixed point theorems with applications to Volterra integral equations, Fixed Point Theory Appl., 2013:196, (2013)

[12] Hussain, N., Parvaneh, V., Roshan, J. R. and Kadelburg, Z., Fixed points of cyclic weakly $(\psi, \varphi, L, A, B)$ contractive mappings in ordered b-metric spaces with applications, Fixed Point Theory Appl., 2013:256, (2013)

[13] Hussain, N., Salimi, P. and Vetro, P., Fixed points for $\alpha-\psi$-Suzuki contractions with applications to integral equations, Carpath. J. Math., 30 (2014), 197-207

[14] Hussain, N. and Abbas, M., Common fixed point results for two new classes of hybrid pairs in symmetric spaces, Appl. Math. Comput., 218 (2011), 542-547

Received: 25.08.2015; In revised form: 28.08.2016; Accepted: 27.09.2016

2010 Mathematics Subject Classification. 47H10, 54H25, 55M20.

Key words and phrases. Fixed point, F-contractions, metric space.

Corresponding author: N. Hussain; nhusain@kau.edu.sa 
[15] Kutbi, M. A., Ahmad, J., Hussain, N. and Arshad, M., Common fixed point results for mappings with rational expressions, Abstr. Appl. Anal., 2013:(2013), 1-11

[16] Piri, H. and Kumam, P., Some fixed point theorems concerning F-contraction in complete metric spaces, Fixed Point Theory Appl., 2014:210, (2014)

[17] Secelean, N. A., Iterated function systems consisting of F-contractions, Fixed Point Theory Appl., 2013:277, (2013)

[18] Suzuki, T., A generalized Banach contraction principle that characterizes metric completeness, Proc. Amer. Math. Soc., 136 (2008), 1861-1869

[19] Wardowski, D., Fixed points of a new type of contractive mappings in complete metric spaces, Fixed Point Theory Appl., 2012:94, (2012)

Department OF MATHEMATics

KING ABDULAZIZ UNIVERSITY

P.O. BOX 80203, JEDDAH 21589, SAUDI ARABIA

E-mail address: nhusain@kau.edu.sa

DEPARTMENT OF MATHEMATICS

UNIVERSITY OF JEDDAH

P. O. BOX 80327, JEDDAH 21589, SAUdi ARABIA

E-mail address: jamshaid_jasimeyahoo.com 